\title{
Oral fluticasone propionate in active distal ulcerative colitis
}

\author{
P Angus, J A Snook, M Reid, D P Jewell
}

\begin{abstract}
Fluticasone propionate is a new corticosteroid with low systemic bioavailability. This study reports the outcome of a double blind clinical trial comparing oral fluticasone propionate (5 $\mathrm{mg}$ four times daily) with placebo for the treatment of active distal ulcerative colitis. Sixty patients were treated for four weeks, with assessments at two and four weeks. One patient was withdrawn when she was found to have amoebiasis. Thus, results are presented for 29 patients who received placebo and 30 who received fluticasone propionate. The two groups were well matched for age, sex, length of history, and extent of disease. After four weeks of therapy the clinical, sigmoidoscopic, and histological responses were similar in the two groups. It is concluded that fluticasone propionate (5 $\mathrm{mg}$ four times daily) is not effective treatment for active distal ulcerative colitis.
\end{abstract}

Corticosteroids have proved highly effective in the treatment of acute attacks of ulcerative colitis but their use is mitigated by side effects. Thus, the development of a corticoid with low systemic bioavailability would be a considerable advance. Several steroid compounds that have been shown to give very low blood concentrations and hence have no effect on the hypothalamic-pituitaryadrenal axis are available for topical use. These include betamethasone, ${ }^{1}$ beclomethasone- $17 \mathrm{val}$ erate, ${ }^{2}$ and prednisolone metasulphobenzoate, ${ }^{3}$ all of which are effective treatments for active distal ulcerative colitis. More recently, tixocortol pivalate $^{4}$ and budesonide ${ }^{5}$ have also proved as effective as a steroid enema.

Fluticasone propionate is a new corticosteroid with low systemic bioavailability because of poor absorption from the gastrointestinal tract and considerable first pass metabolism (Glaxo Group Research - personal communication). When given in a single oral dose to patients with a well established ileostomy, $72 \cdot 7 \%$ of the drug was recovered in the ileostomy effluent (J A Snook and D P Jewell; unpublished observations).

The purpose of this study was to evaluate, over a four week period, the efficacy and safety of 20 $\mathrm{mg}$ of fluticasone propionate given orally in divided doses ( $5 \mathrm{mg}$ four times daily) compared with placebo for the treatment of active ulcerative colitis.

\section{Patients and methods}

As the study was placebo-controlled, entry was restricted to patients (aged 18-65 years) with mild or moderately active ulcerative colitis that did not extend beyond the splenic flexure. Patients had to be systemically well and to be passing more than three but less than seven motions daily. Before inclusion, the presence of active inflammation was confirmed by rigid sigmoidoscopy. In all patients, the extent of the disease had been established within the previous five years by either colonoscopy or barium radiology.

Pregnant or breastfeeding women and patients with significant cardiovascular, renal, hepatic, or metabolic diseases were ineligible for inclusion.

The study was approved by the Central Oxfordshire Research and Ethics Committee. Written consent was obtained from each patient after a full explanation of the trial.

\section{DRUGS AND DOSAGES}

Fluticasone propionate (5 mg tablets) and matching placebo tablets were provided by Glaxo Group Research Ltd. The active drug was used at a dose of $20 \mathrm{mg}$ daily.

\section{STUDY DESIGN}

Patients were randomly allocated to receive either fluticasone propionate $(5 \mathrm{mg}$ four times daily) or matching placebo tablets (one, four times daily) for four weeks. The randomisation code was generated using an in-house Glaxo program, PACT (Patient Allocation for Clinical Trials). Patients were randomised in blocks of six.

Concomitant treatment with systemic or topically active steroids of any kind was not permitted during the study and patients who had received such medication within the previous 14 days were excluded. Patients were allowed to continue longterm treatment with sulphasalazine, mesalazine, or olsalazine at the same dose provided that therapy had already begun before the relapse that brought the patient into the trial.

At the beginning of the study, frequency of bowel actions, stool consistency, and severity of rectal bleeding were noted. The macroscopic appearance of the rectal mucosa was graded 0-3 according to the criteria of Baron et al. ${ }^{6}$ Based on the symptoms, clinical signs, and endoscopic 
findings, an overall physician's impression was given as follows: 0 -remission, 1-mild, 2-moderate, 3-severe, and 4-fulminant disease. A rectal biopsy specimen was taken and the severity of the inflammation seen on histological sections stained with haematoxylin and eosin was graded according to the criteria of Powell-Tuck et al. ${ }^{7}$ The histopathologist (MR) was unaware of the patients' clinical findings. A full physical examination was performed at entry and blood samples were taken for routine haematology, biochemistry, and measurement of erythrocyte sedimentation rate, C-reactive protein, and orosomucoids. Urine analysis was performed at each visit.

Patients were seen in the outpatient clinic at two and four weeks after starting treatment. At both visits, symptom assessment, sigmoidoscopic and histological grading of disease activity, general examination, and blood tests were repeated.

The effect of treatment on endogenous corticosteroid production was monitored by comparing cortisol concentrations in saliva at $9.00 \mathrm{am}$ on day 1 of the study (before entry) with the concentrations on day 28 of treatment or at the time of withdrawal. The cortisol was measured by direct radioimmunoassay by BioClinical Services Ltd, Cardiff.

\section{STATISTICAL ANALYSIS}

The number of patients to be recruited was calculated assuming a remission rate of $80 \%$ with fluticasone propionate and $35 \%$ with placebo. Type 1 error, 2-tail, was set at 0.05 and type 2 error, 1-tail, set at $0 \cdot 1$ to give a power of $90 \%$. This gave a total sample size of 60 patients allowing for a proportion of non-assessable cases.

Comparison of the changes in symptoms, signs, and histological scores after four weeks was performed using the $\chi^{2}$ test. The Student's $t$ test was used to compare mean salivary cortisol concentrations. Results were considered significant if $\mathrm{p}$ was $<0 \cdot 05$.

\section{Results}

Sixty patients were recruited into the study. However, one patient was withdrawn after the biopsy report at 14 days which described amoebiasis. She had been successfully treated for ulcerative colitis during the previous two years but she was excluded from all subsequent analysis. Therefore, data from 59 patients have been analysed on an intention to treat basis; 29 received placebo and 30 received fluticasone propionate. The demographic and clinical characteristics of the two groups were similar and are shown in Table I. Forty nine patients completed the study. Nine were withdrawn (6 fluticasone propionate, 3 placebo) during the course of the trial due to lack of response (day of withdrawal ranged from 5-18). One additional patient on fluticasone propionate was withdrawn after an adverse event (see later).

ASSESSMENT OF DISEASE ACTIVITY

For those who completed four weeks of treatment, similar numbers of patients in each group noted improvement in their symptoms of colitis (Table II). The physician's overall assessments showed that 14 of 30 patients $(47 \%)$ treated with fluticasone propionate had improved or gone into remission by the end of the trial compared with 13 of $29(45 \%)$ receiving placebo $(p=0 \cdot 888)$. Only four patients receiving fluticasone propionate and five on placebo were considered to be in remission as defined by the absence of symptoms and quiescent disease on sigmoidoscopy.

The sigmoidoscopic gradings at four weeks (or at the time of withdrawal) improved by at least one grade in 13 in the fluticasone propionate group (43\%) compared with 14 in the placebo group $(48 \%)(p=0 \cdot 706)$. In one patient on fluticasone propionate and in four receiving placebo the sigmoidoscopic appearances returned to normal (grade 0 ).

Forty eight of the 49 patients who completed the study had adequate rectal biopsy specimens taken at their last visit. The improvement in histological scores was similar in the two groups 11 showing improvement in the fluticasone propionate group (48\%) compared with nine in the placebo group (36\%), $p=0 \cdot 411$. Complete resolution of inflammation was noted in the biopsy specimens of only one fluticasone propionate patient and two placebo patients.

TABLE I Patient characteristics

\begin{tabular}{|c|c|c|}
\hline & \multicolumn{2}{|l|}{ Group } \\
\hline & $\begin{array}{l}\text { Fluticasone } \\
\text { propionate }\end{array}$ & Placebo \\
\hline Sex: Male & 18 & 12 \\
\hline Female & 12 & 17 \\
\hline $\begin{array}{l}\text { Age (years): } \\
\text { Median (range) }\end{array}$ & & \\
\hline $\begin{array}{l}\text { Weight }(\mathrm{kg}) \text { : } \\
\text { Mean (SD) }\end{array}$ & $73.3(13.9)$ & $68 \cdot 7(11 \cdot 8)$ \\
\hline $\begin{array}{l}\text { Temperature }\left({ }^{\circ} \mathrm{C}\right) \text { : } \\
\text { Mean }(\mathrm{SD})\end{array}$ & $36.5(0.2)$ & $36 \cdot 6(0 \cdot 2)$ \\
\hline $\begin{array}{l}\text { Mean }(\mathrm{SD}) \\
\text { Pulse (beats/min): } \\
\text { Mean (SD) }\end{array}$ & $73(6)$ & $75(8)$ \\
\hline $\begin{array}{l}\text { Length of history (months): } \\
\text { Median (range) }\end{array}$ & $\begin{array}{l}72 \\
(2-240)\end{array}$ & $\begin{array}{l}48 \\
(2-240)\end{array}$ \\
\hline $\begin{array}{l}\text { Duration of current symptoms (weeks): } \\
\text { Median (range) }\end{array}$ & $\begin{array}{l}4 \\
(2-32)\end{array}$ & $\stackrel{8}{(1-24)}$ \\
\hline Extent of disease: & & \\
\hline Rectum & 14 & 12 \\
\hline Rectosigmoid & 6 & 6 \\
\hline To splenic flexure & 10 & 11 \\
\hline
\end{tabular}

TABLE II Percentage of patients completing the trial who reported an improvement in symptoms

\begin{tabular}{llll}
\hline & Group & \\
\cline { 2 - 3 } & $\begin{array}{l}\text { Fluticasone } \\
\text { propionate } \\
(n=23)\end{array}$ & $\begin{array}{l}\text { Placebo } \\
(n=26)\end{array}$ & Significance \\
\hline Bowel frequency & 54 & 58 & $\mathrm{p}=0.804$ \\
Stool consistency & 40 & 52 & $\mathrm{p}=0.430$ \\
Blood in stools & 36 & 39 & $\mathrm{p}=0.850$ \\
\hline
\end{tabular}

* Only 22 in the fluticasone propionate group and 23 in the placebo group reported blood on entry.

TABLE III Salivary cortisol concentrations (nmol/l, mean $(S D))$

\begin{tabular}{lllll}
\hline & \multicolumn{3}{l}{ Group } & \\
\cline { 3 - 4 } & No. & $\begin{array}{l}\text { Fluticasone } \\
\text { propionate }\end{array}$ & Placebo & Significance \\
\hline At entry & 25 & $11 \cdot 0(16 \cdot 0)$ & $8 \cdot 4(8 \cdot 1)$ & \\
After 28 days & 21 & $6 \cdot 4(4 \cdot 8)$ & $9 \cdot 1(6 \cdot 1)$ & $\mathrm{p}=0.0849$ \\
\hline
\end{tabular}

Normal range $5-25 \mathrm{nmol} / \mathrm{l}$ 
Changes in haemoglobin, platelet count, erythrocyte sedimentation rate, C-reactive protein, orosomucoids, and serum albumin were similar for both groups at two and four weeks.

\section{SALIVARY CORTISOI}

Eighteen patients in the fluticasone propionate group and 20 in the placebo group returned adequate salivary samples on entry and at day 28 . There was no significant change in the mean salivary cortisol concentrations in either group at the end of the study (Table III).

\section{ADVERSE EVENTS}

Two patients who received fluticasone propionate (rash on arms (1), tension headache (1), and three who received placebo (herpes labialis (2), light-headedness (1)) reported trivial adverse events that resolved or improved with continuing treatment. One further patient in the fluticasone propionate group developed an acute oligoarthritis two days before completion of the trial. This patient had not improved during the course of the trial and the arthritis was considered to be related to active ulcerative colitis rather than the effect of fluticasone propionate treatment. Both the colitis and the joints responded rapidly to subsequent treatment with prednisolone.

One other patient in the fluticasone propionate group developed a more serious adverse reaction. A 43 year old woman with no history of diabetes and a normal pretreatment plasma glucose concentration, was noted to have glycosuria and a raised plasma glucose value $(20.9 \mathrm{mmol} / \mathrm{l})$ after two weeks of treatment and was subsequently withdrawn from the trial. At the time of withdrawal, the patient's symptoms of colitis had resolved, the sigmoidoscopic appearance of the rectal mucosa was normal, and histological examination of the rectal biopsy specimen showed resolution of the active inflammation. Her salivary cortisol concentration had fallen from $15 \mathrm{nmol} / \mathrm{l}$ on day 1 to unmeasurable levels on the day of withdrawal. It was felt that the hyperglycaemia was almost certainly due to a systemic effect of the drug. Blood glucose concentrations returned to normal within two days of stopping therapy and the patient subsequently remained normoglycaemic.

\section{Discussion}

Preliminary studies in animals and in human volunteers indicated that oral fluticasone propionate has poor systemic bioavailability. As a preliminary study to the therapeutic trial, eight patients with a well established ileostomy (all patients having had ulcerative colitis) were given a single oral dose of $5 \mathrm{mg}$ fluticasone propionate. Ileostomy effluent was collected over the subsequent 24 hour period in three aliquots $(0-6$, $6-12,12-24$ hours). Fluticasone propionate was subsequently assayed and the mean recovery rate was $72 \cdot 7 \%$ (range $45 \cdot 7-97 \cdot 6 \%$ ), mostly within 12 hours. (J A Snook and D P Jewell; unpublished observations). It was therefore hoped that, in patients with colitis, the drug would reach the colon in sufficient quantities to suppress the inflammation while avoiding the systemic side effects of other corticosteroid preparations.

This trial indicates that, in a dose of $20 \mathrm{mg}$ daily, fluticasone propionate is no more effective than placebo in the treatment of active ulcerative colitis. It is possible that the results were compounded by the high placebo response but this degree of response has been noted in previous placebo controlled studies. ${ }^{89}$ However, there was not even a trend in favour of fluticasone propionate and, although many patients showed improvement, few in either group (13\% fluticasone propionate, $17 \%$ placebo) actually went into clinical remission. Furthermore, the power of the study was such that even with a placebo response of $40 \%$, the probability of failing to detect a true benefit of fluticasone propionate over placebo was less than $5 \%$.

Since topical corticosteroids are known to be effective in the treatment of active ulcerative colitis, and fluticasone propionate has a topical action in the bronchial tree, ${ }^{10}$ why was it not effective in this trial? Perhaps the most likely explanation is that the drug did not reach the site of disease in sufficient concentration or in the appropriate form. None of the patients in the study had colitis that extended beyond the splenic flexure and in many (approximately two thirds) the disease was confined to the rectosigmoid. After defecation, even in patients with diarrhoea, the distal colon is likely to be largely empty of faeces for some time. Thus, the most actively inflamed part of the colon might only be exposed to the drug intermittently. Furthermore, in patients with diarrhoea, the concentrations of fluticasone propionate achieved in the colon may be considerably lower than those achieved in controls. Studies of the faecal excretion of fluticasone propionate in patients will be required to answer these questions.

Although, in general, the drug was well tolerated, one patient developed hyperglycaemia with evidence of suppression of endogenous corticosteroid production. There was no reason to suspect drug overdosage or liver dysfunction in this patient and her colitis did not seem to be more active or more extensive than in many other patients in the trial. Thus, it must be assumed that this patient's hyperglycaemia was due to the systemic effect of the drug. It is of interest that the colitis went into complete remission at two weeks, which might also suggest an abnormal systemic bioavailability of the drug.

In conclusion, oral fluticasone propionate, 5 mg four times daily is not effective treatment for active distal ulcerative colitis. More knowledge of the pharmacodynamics of the drug may be helpful to design studies using higher concentrations. It is possible that the drug will prove more effective in the treatment of inflammation in the small bowel or in the proximal colon.

We are grateful for generous support and advice given by Glaxo Group Research Ltd.

1 Multicentre Trial. Betamethasone 17-valerate and prednisolone 21-phosphate retention enema in proctocolitis. $B M$ 1971; ii: 84-6.

2 Kumana CR, Seaton T, Meghii M, Castelli M, Benson R, Sivakumaran T. Beclomethasone dipropionate enemas for treating inflammatory bowel disease without producing Cushing's syndrome or hypothalmic pituitary suppression. Lancet 1982; i: 579-82. 
3 McIntyre PB, Macrae F, Berghouse L, English J, LennardJones JE. Therapeutic benefits from a poorly absorbed prednisolone enema in distal colitis. Gut 1985; 26: 822-4

4 Hanauer SB. Clinical experience with tixocortol pivalate. Can f Gastroenterol 1988; 2: 156-8.

5 Danielsson A, Hellers G, Lyrenas E, Löfberg R, Nilsson A Olsson $\mathrm{O}$, et al. A controlled randomised trial of budesonide versus prednisolone retention enemas in active distal colitis. Scand 7 Gastroenterol 1987; 22: 987-92.

6 Baron JH, Connell AM, Lennard-Jones JE. Variation between observers in describing mucosal appearances in proctocolitis. BMF 1964; i: 89-92.
7 Powell-Tuck J, Day DW, Bucknell NA, Wadsworth J Lennard-Jones JE. Correlations between defined sigmoidoscopic appearances and other measures of disease activity in ulcerative colitis. Dig Dis Sci 1982; 27: 533-7.

8 Selby WS, Barr GD, Ireland A, Mason CH, Jewell DP. Olsalazine for the treatment of active ulcerative colitis. $B M \mathcal{F}$ 1985; 291 : 1373-5.

9 Burke DA, Axon ATR, Clayden SA, Dixon MF, Johnston D Lacey RW. The efficacy of Tobramycin in the treatment of ulcerative colitis. Aliment Pharmacol Therap 1990; 4: 123-9. 10 Bauer K, Bamtje TA, Sips AR, Bogaerts YJM, Gillard C, Kardos P, et al. Eur Respir 7 1988; 1 (suppl 2): 201. 